\title{
Changes in Bone Turnover, Inflammatory, Oxidative Stress, and Metabolic Markers in Women Consuming Iron plus Vitamin D Supplements: A Randomized Clinical Trial
}

\author{
Behnaz Abiri \\ Ahvaz Jondishapour University of Medical Sciences \\ Fatemeh Azizi-Soleiman \\ Isfahan University of Medical Sciences \\ Mohammadreza Vafa ( $\nabla$ rezavafa@yahoo.com) \\ Iran University of Medical Sciences \\ Morteza Safavi \\ Isfahan University of Medical Sciences

\section{Seyyed Morteza Kazemi} \\ Shaheed Beheshti University of Medical Sciences \\ Masood Salehi \\ Iran University of Medical Sciences \\ Farid Zaeri \\ Shaheed Beheshti University of Medical Sciences \\ Homa Sadeghi \\ Texas Woman's University
}

\section{Research}

Keywords: vitamin D, iron, bone turnover, inflammation, oxidative Stress

Posted Date: December 16th, 2019

DOI: https://doi.org/10.21203/rs.2.18692/v1

License: (c) (i) This work is licensed under a Creative Commons Attribution 4.0 International License. Read Full License

Version of Record: A version of this preprint was published at Biological Trace Element Research on September 25th, 2020. See the published version at https://doi.org/10.1007/s12011-020-02400-8. 


\section{Abstract}

Background We aimed to investigate whether combination of vitamin $D$ and iron supplementation, comparing vitamin $D$ alone, could modify bone turnover, inflammatory, oxidative stress, and metabolic markers.

Methods Women with hemoglobin $(\mathrm{Hb}) \leq 12.7 \mathrm{~g} / \mathrm{dL}$ and $250 \mathrm{HD} \leq 29 \mathrm{ng} / \mathrm{mL}$ vitamin D deficiency/insufficiency aged $18-45$ years $(\mathrm{n}=100)$ were recruited into a trial to receive either $1000 \mathrm{IU} / \mathrm{d}$ vitamin D3 plus $27 \mathrm{mg} / \mathrm{d}$ iron (D-Fe) or vitamin D3 plus placebo supplements (D-P) for 12 weeks.

Results In D-Fe group, significant decreases in red blood cells (RBC) $(P=0.001)$, hematocrit (Hct) $(P=0.004)$ and increases in mean corpuscular hemoglobin concentration $(\mathrm{MCHC})(\mathrm{P}=0.001), 250 \mathrm{HD}(\mathrm{P}<0.001)$, osteocalcin $(\mathrm{P}<0.001)$, high-density cholesterol $(\mathrm{HDL})$ $(P=0.041)$, and fasting blood sugar $(F B S)(P<0.001)$ were observed. D-P group showed significant decreases of $R B C(P<0.001), H b(P<0.001)$, Hct $(P<0.001)$, mean corpuscular volume (MCV) $(P=0.004)$, mean corpuscular hemoglobin $(M C H)(P<0.001), M C H C(P=0.005)$, serum ferritin $(P<0.001)$, and low-density cholesterol $(L D L)(P=0.016)$ and increases of $250 H D(P<0.001)$, osteocalcin $(P<0.001)$, $C$-terminal telopeptide (CTX) ( $P=0.025)$, triglyceride (TG) ( $P=0.004)$, FBS ( $P<0.001)$, and interleukin-6 (IL-6) $(P=0.001)$ at week 12. After the intervention, the $D-P$ group had between-group increases in mean change in the osteocalcin $(P=0.007)$ and IL-6 $(P=0.033)$, and decreases in the RBC $(P<0.001)$, $\mathrm{Hb}(P<0.001)$, Hct $(P<0.001)$, MCV $(P=0.001)$, compared to the $D-F e$ group. There were significant between-group changes in $M C H(P<0.001)$, MCHC $(P<0.001)$, ferritin $(P<0.001)$, and serum iron $(P=0.018)$.

Conclusions Iron-vitamin D co-supplementation does not yield added benefits for improvement of bone turnover, inflammatory, oxidative stress, and metabolic markers; whereas, vitamin D alone may have some detrimental effects on inflammatory and metabolic markers.

\section{Introduction}

Vitamin D deficiency and anemia are problems that are still common in the world. It has been estimated that more than a billion people around the world suffer from hypovitaminosis $\mathrm{D}(250 \mathrm{HD} \leq 75 \mathrm{nmol} / \mathrm{L}(<30 \mathrm{of} \mathrm{ng} / \mathrm{ml}))[1]$.Furthermore, the global prevalence of anemia was estimated at 1.62 billion people between 1993 and 2005, mostly caused by iron deficiency [2].

Vitamin D has several valuable functions. Severe vitamin D deficiency $(250 \mathrm{HD} \leq 15 \mathrm{nmol} / \mathrm{ml}$ ) causes rickets in children and osteomalacia in adults, and eventually bone fractures[3]. The reason is attributed to secondary hyperparathyroidism and a consequent increase in bone turnover. Vitamin D supplementation may improve bone mass density and reduce bone turnover and risk of fracture [4]. Additionally, production of inflammatory cytokines such as tumor necrosis factor-a (TNF-a), interferon- $y$, interleukin-2, interleukin-9 and interleukin-22, is inhibited by vitamin D. whereas; production of anti-inflammatory cytokines such as interleukin-3, interleukin-4, interleukin- 5 and interleukin-10 is initiated by vitamin $D$ [5]. It has also been demonstrated that risk of diseases associated with increased DNA damage, caused by oxidative stress, is more in patients with vitamin D deficiency or insufficiency [6]. Researchers suggested that vitamin D may improve some of cardiovascular diseases risk factors such as serum lipids, fasting plasma glucose, and oxidative stress [7, 8].

Recent years, the relationship between anemia and vitamin d deficiency has attracted a great deal of attention from researchers. A low level of vitamin D in Asian children with IDA has been reported [9, 10]. A recent systematic review showed a positive relationship between iron status and vitamin $D$ [11]. One of the possible explanations has been discussed in the literature is the role of iron in the hydroxylation of vitamin D by cytochrome P450 isoforms [12]. These enzymes are dependent on electron donors including ferredoxin and ferredoxin reductase which contain heme group. The effect of iron on vitamin $D$ activation is controversial; Intramuscular injection of iron in irondeficient infants increased vitamin D levels after 2 months[13], while treatment of iron deficiency in adult women had no effect on 250HD concentrations [14]. Additionally, iron as a cofactor for lysyl prolyl hydroxylase enhances bone strength [15] and its chronic deficiency may lead to osteoporosis in later life. A positive relationship between bone mass density at the proximal radius and serum ferritin levels has been reported in adolescent girls [16].

To the best of our knowledge, few interventional studies have investigated the effects of iron supplementation on vitamin D concentration, bone turnover, cardiometabolic, inflammatory and oxidative stress biomarkers. The present study aimed to investigate whether combination of vitamin $\mathrm{D}$ and iron supplementation, comparing vitamin $\mathrm{D}$ and placebo, could modify vitamin $\mathrm{D}$ status, some bone turnover markers, selected markers of inflammation and oxidative stress, lipid profiles, and glucose level in child-bearing age women with low levels of hemoglobin $(\mathrm{Hb})$ and vitamin $\mathrm{D}$.

\section{Materials And Methods}


This study was a triple-blind, randomized, clinical trial conducted in Kermanshah, Iran, during May-August 2015.700 women aged 18-45were recruited at health care centers and screened for vitamin D deficiency and anemia. Inclusion criteria were as follows: healthy women, nonsmoker, non-pregnant, non-lactating, have a body mass index (BMI) between 18.5-29.9, with $\mathrm{Hb} \leq 12.7 \mathrm{~g} / \mathrm{dL}$ and $250 \mathrm{HD}<30 \mathrm{ng} / \mathrm{mL}$. Iron deficiency anemia is diagnosed with hemoglobin levels less than $12 \mathrm{~g} / \mathrm{dL}$. However, Beutler and Waalen have suggested considering the altitude of the residence site of people for the screening of anemia[17]; as this cut-off could be increased to $4 \%$ per 1000 meters above sea level[18], $\mathrm{Hb} \leq 12.7 \mathrm{~g} / \mathrm{dL}$ was used for anemia screening. Vitamin D deficiency was defined as $250 \mathrm{HD}<20 \mathrm{ng} / \mathrm{mL}$ and vitamin D insufficiency as a level of $20-29 \mathrm{ng} / \mathrm{mL}[19]$.

Females were excluded if they had amenorrhea, menopause, thalassemia, hemochromatosis, inflammatory bowel diseases, Crohn's disease, gastric ulcers, celiac disease, gastrointestinal bleeding disorders, kidney diseases, blood donation or taking any kind of medications with an impact on hematologic and biochemical markers during 4 past months (i.e., dietary supplements and drugs like nonsteroidal antiinflammatory, anti-diabetic, or lipid-lowering agents). The sample size was calculated for detecting a $21.1 \mathrm{ng} / \mathrm{mL}$ increase [20] in the concentrations of vitamin D in Fe-D group as compared with P-D group, according to the dose of vitamin D used in the present study, at a significance level of 0.05 and $90 \%$ power. A study size of 76 females was obtained. Assuming a $25 \%$ drop-out rate, a total of 100 women participated in the intervention. As most of screened women had normal hemoglobin levels ( $\geq 12.7 \mathrm{~g} / \mathrm{dL})$, totally, 100 women were recruited onto the trial. Baseline characteristics of participants are shown in Table 1.

This study was in agreement with the declaration of Helsinki and was approved by the Ethics Committee of the Isfahan University of Medical Sciences (IR.mui.rec.1394.3 / 291) and the Iran University of Medical Sciences (94-02-27-25971). Written informed consent was obtained from all participants after explaining the purpose and process of the study, and the intervention was registered at www.irct.ir, IRCT201409082365N9. This study followed the CONSORT guidelines and the details of trial are presented in Fig. 1.

An independent researcher used a random allocation sequence to randomly allocate females in a 1:1 ratio to receive 1000 IU cholecalciferol and $27 \mathrm{mg}$ ferrous sulfate plus $100 \mathrm{mg}$ ascorbic acid or $1000 \mathrm{IU}$ cholecalciferol and matched placebo in terms of shape, color, and taste for 12 weeks. Vitamin D, iron, and placebo tablets were manufactured by Jalinous (Jalinous pharmaceutical Company, Tehran, Iran), Maad (Maad Pharmacy, Tehran, Iran), and Tehran University of Medical Sciences (Roshd Pharmaceutical Incubation Center, Tehran, Iran), respectively. The independent researcher packaged iron and placebo tablets in boxes and consecutively numbered according to a computergenerated randomization list. Using opaque envelopes, the boxes were delivered to the study supervisor for random allocation. An order number was assigned to each female and the supplements were given in the corresponding pre-packed box every 4 weeks. The allocation was masked from the participants, study supervisor, staff involved in outcome assessment, and statistician until drafting results.

Women were instructed to take both tablets daily and not change their habitual dietary intake and physical activity. Compliance with the intervention was assessed using the levels of $250 \mathrm{HD}$, serum iron, and number of remaining pills. Additionally, all participants were contacted monthly during the study period.

\section{Primary outcome}

The concentration of 250HD was measured at baseline and 12 weeks. Blood samples were collected at the time of screening and at the end of the intervention after a 12-h fasting period. Whole blood (3 cc) was used to assess complete cell blood count. Serum was obtained from remaining blood after centrifugation at $1000 \mathrm{~g}$ for $15 \mathrm{~min}$, stored at $-80^{C}$, and analyzed after the study was completed. Serum vitamin $\mathrm{D}$ was measured by an ELISA kit, with intra- and inter-assay coefficients of variation of 5.6 and 6.4\%, respectively (25-hydroxyvitamin D EIA, Immunodiagnostic Systems, IDS, United Kingdom).

\section{Secondary outcome}

Secondary outcomes included hematologic indices (complete cell blood count, ferritin, serum iron, transferrin saturation, and total iron binding capacity (TIBC), bone turnover markers (osteocalcin, C-terminal telopeptide (CTX), parathyroid hormone (PTH), alkaline phosphatase (ALP) enzyme activity and enzyme mass), inflammatory markers (interleukin-6, TNF-a, high sensitivity C-reactive protein (hsCRP), oxidative stress markers (total antioxidant capacity (TAC) and malondialdehyde, fasting blood sugar (FBS), and lipid profile (total cholesterol (TC), low-density cholesterol (LDL), low-density cholesterol (HDL), and triglyceride (TG). Measurement of ferritin was done by an ELISA kit. Sensitivity and intra-assay coefficient of variation for ferritin were $0.5 \mathrm{ng} / \mathrm{mL}$ and $8.7 \%$, respectively. Serum iron was measured using enzymatic photometry. Transferrin was defined by the immunotorbidimetric method.

The bone formation marker, serum osteocalcin, was measured by an ELISA commercial kit with $0.25 \mathrm{ng} / \mathrm{mL}$ sensitivity and intra-assay coefficient of variation of $5.7 \%$ (ZellBio $\mathrm{GmbH}$, Ulm, Germany). The bone resorption marker, serum CTX, was determined by an ELISA commercial kit with $10 \mathrm{pg} / \mathrm{mL}$ sensitivity and intra-assay coefficient of variation of $6.1 \%$ (ZellBio GmbH, Ulm, Germany). PTH was measured 
with the use of an ELISA kit (ZellBio GmbH, Ulm, Germany, sensitivity: $0.8 \mathrm{pg} / \mathrm{mL}$ and intra-assay coefficient of variation: $5.4 \%$ ). ALP mass was defined using an ELISA commercial kit (ZellBio GmbH, Ulm, Germany, sensitivity: $0.1 \mathrm{ng} / \mathrm{mL}$ and intra-assay coefficient of variation:5.8\%) and ALP activity was measured by colorimetry.

HsCRP was measured with the use of an ELISA kit (Diagnostics Biochem Canada Inc., ontario, Canada, sensitivity: 10 ng/mL and intra-assay coefficient of variation: 6.2\%). Serum interleukin- 6 was determined by an ELISA commercial kit with 2 pg/mL sensitivity (Diaclone, Besancon, France). Serum TNF-a was measured by an ELISA commercial kit with $8.5 \mathrm{pg} / \mathrm{mL}$ sensitivity and intra-assay coefficient of variation of $6.6 \%$ (Diaclone, Besancon, France). TAC was defined as using an ELISA commercial kit (ZellBio GmbH, Ulm, Germany, sensitivity: 0.1 mM and intra-assay coefficient of variation: $5.1 \%$ ) and malondialdehyde was measured by an ELISA commercial kit (ZellBio GmbH, Ulm, Germany, sensitivity: $0.1 \mathrm{mM}$ and intra-assay coefficient of variation: $4.8 \%$ ). FBS and lipid profiles were measured by enzymatic colorimetric methods.

Height was measured to the nearest $0.1 \mathrm{~cm}$ using a stadiometer. Body weight was measured to the nearest $100 \mathrm{~g}$ on a scale. BMI was calculated as weight $(\mathrm{kg}) /$ height $(\mathrm{m})^{2}$. The body fat mass was determined with the same scale used for measuring weight. Dietary intake was supposed to assessed using a 3-day food record; because of low cooperation of individuals, it was evaluated both before and after the intervention using a $24 \mathrm{~h}$ recall and daily energy, macro- and micro-nutrients intake were calculated with Nutritionist IV software. Physical activity level was assessed using International Physical Activity Questionnaire, short format [21], at baseline and the end of the study. Sun exposure was defined by a validated questionnaire[22].

\section{Statistical analysis}

Statistical analyses were performed using SPSS software (IBM Corp. Released 2013. IBM SPSS Statistics for Windows, Version 22.0. Armonk, NY: IBM Cor) and P-value < 0.05 was considered statistically significant. Normal distribution of outcome variables was defined using the Shapiro-Wilk test. Changes within groups from baseline to week 12 were analyzed using Paired Samples T-tests or Wilcoxon Signed Ranks test whenever the distribution of the variables were not normal. Change on each variable was calculated as pre-intervention minus post-intervention values for each subject and then mean value for the change for each group was calculated. To compare mean changes in variables between groups, the Mann-Whitney or Independent Samples T-test were used. One-way analysis of covariance (ANCOVA) was also conducted to adjust the effect of baseline differences on the intervention results, whenever there were significant differences in baseline values between groups. Continuous variables are presented as mean and standard deviations (Mean \pm SD). Categorical variables are demonstrated as frequencies and percentages. Chi-square test was used to assess the differences between categorical variable.

\section{Results}

Ages of the volunteers were $35.18 \pm 6.74$ and $34.08 \pm 7.64$ years for the D-P and D-Fe groups, respectively, without significant differences between groups (Table 1). No significant differences between groups were found in body weight, BMI, and physical activity level at baseline.

A total of 87 women completed the study. Eleven women dropped out in the D-P group; nine of them refused further participation in the study because of personal reasons and two of them withdrew due to getting pregnant. Two females in the D-Fe group were excluded due to gastrointestinal complaints.

Table 2 shows the intervention results. There were significant differences in baseline values of red blood cells $(P=0.013), M C V(P=0.006)$, $\mathrm{MCH}(P=0.006)$, ferritin $(0.041)$, alkaline phosphatase enzyme mass $(P=0.034)$, alkaline phosphatase enzyme activity $(P=0.033), C T X(P=$ $0.032)$, parathyroid hormone $(P=0.045)$, hsCRP $(0.007)$, total antioxidant capacity $(P=0.005)$, total cholesterol $(P=0.008)$, triglyceride $(P=$ 0.011), LDL $(P=0.006)$, and HDL $(P=0.008)$ between D-Fe and D-P groups.

In D-Fe group, significant decreases in red blood cells $(P=0.001)$, hematocrit $(P=0.004)$, weight $(P=0.012)$ and increases in $250 H D(P<$ 0.001), $\mathrm{MCHC}(P=0.001)$, osteocalcin $(P<0.001)$, fasting blood sugar $(P<0.001)$, and HDL $(P=0.041)$ and were observed. $D-P$ group showed significant decreases of RBC $(P<0.001), \mathrm{Hb}(P<0.001)$, hematocrit $(P<0.001), \mathrm{MCV}(P=0.004), M C H(P<0.001), M C H C(P=0.005)$, serum ferritin $(P<0.001)$, and LDL $(P=0.016)$ and increases of $250 H D(P<0.001)$, osteocalcin $(P<0.001), C T X(P=0.025)$, fasting blood sugar $(P<0.001)$, interleukin-6 $(P=0.001)$, and triglyceride $(P=0.004)$ at week 12 .

After the intervention, the D-P group had between-group decreases in mean change in the red blood cells $(P<0.001)$, hemoglobin $(P<0.001)$, hematocrit $(P<0.001)$, MCV $(P=0.001)$, and increases in the osteocalcin $(P=0.007)$ and interleukin-6 $(P=0.033)$, compared to the $D-F e$ group. There were significant between-group changes in $\mathrm{MCH}(P<0.001), \mathrm{MCHC}(P<0.001)$, ferritin $(P<0.001)$, and serum iron $(P=0.018)$. Though $\mathrm{MCH}, \mathrm{MCHC}$ and serum iron increased in the D-Fe group, these variables decreased in the D-P group. Controlling for pre-intervention variance by ANCOVA did not change the results for indices that had different initial values, except for triglyceride. The increase in triglyceride concentration was higher in the D-P group after adjusting for baseline values $(P=0.016)$.

Page 4/15 
Dietary characteristics of the females at baseline and week 12 are presented in Table 2. There were no changes in the intake of macro- and micronutrients at week 12 compared to baseline (Table 3). Sun exposure was similar in all volunteers at baseline and after 12 weeks of intervention (Table 4).

\section{Discussion}

This study examined the advantages of adding iron to vitamin D vs. vitamin D alone on bone turnover, inflammatory, oxidative stress, and metabolic markers. The intervention was performed in women with low levels of hemoglobin and 25OHD. However, iron plus vitamin D was not superior to vitamin D alone.

The usefulness of iron therapy in the treatment of anemia has been proven, especially in those with deteriorated hematologic condition [23]. However, supplementation with high dose of ferrous sulfate in female athletes for eleven weeks did not result in an improvement in hematologic parameters and had only a preventive effect on reducing body iron which is in line with the present study [24]. In our study, minor decreases in hematologic indices were observed in the D-Fe group that is physiologically implausible. It has also shown that serum levels of transferrin saturation, ferritin and hemoglobin diminished by using a fortified food product containing calcium and vitamin $D$ during 9 weeks [25]. Failure to see an increase in these variables in the present study could be related to menstruation [26] and insufficient iron dose used [27]. Further studies with different groups and interventions are required.

The salutary effect of vitamin D on bone health is well known. Vitamin D controls bone remodeling through inducing ligand receptor activator of NF-kB, regulation of phosphate homeostasis by increasing fibroblast growth factor 23 , and increase bone response to mechanical stimulation via mitogen-activated protein kinase signaling pathway [28]. It has shown that consumption of 7000 IU/d cholecalciferol for 26 weeks in vitamin D deficient women can reduce PTH and CTX and increase arm bone mass density [29]. A recent study indicated that $1000 \mathrm{IU} /$ day vitamin D supplementation for 9 months decreased bone turnover markers [30]. Lerchbaum et al., evaluated the effects of 20,000 IU/week vitamin D on bone turnover markers in 200 healthy men with $250 \mathrm{HD}<75 \mathrm{nmol} / \mathrm{L}$ in comparison to placebo. However, after 12 weeks of supplementation, there was no significant effect on bone metabolism or density [31]. In our study, it was assumed that vitamin D plus iron supplementation versus vitamin D alone would further increase 250HD concentration, further improve bone formation, and further reduce bone resorption. We observed that both groups experienced approximately the same increase of $250 \mathrm{HD}$, bone turnover markers rose in both groups, and surprisingly, the bone formation marker, osteocalcin, was significantly higher in the D-P group. There are limited studies evaluating the effects of iron on $250 \mathrm{HD}$ and bone turnover markers. Published results of the Safe-D study indicated that factors like age, body composition and iron status have impact on bone turnover markers [32]. Blanco-Rojo et al., reported no effects of iron-fortified juice consumption on bone turnover markers in women with ferritin $<40 \mathrm{ng} / \mathrm{mL}$ [33]. The 250HD levels reduced compared to baseline in both groups, with no difference between groups. In rats fed a diet low in iron, a sharp reduction in the concentration of procollagen type I N-terminal propeptide (bone formation marker) and an increase in PTH and tartrate-resistant acid phosphatase $5 \mathrm{~b}$ (bone resorption markers) have been observed [34]. However, the level of $250 \mathrm{HD}$ in this study did not change. Toxqui et al., observed a decrease in bone turnover markers and an increase in 250HD when a group of women with iron deficiency anemia received an iron and vitamin D-fortified skimmed milk for 16 weeks [35]. A recent study demonstrated no change in serum levels of PTH and vitamin D binding protein after simultaneous supplementation of vitamin D and iron [36]. Recovery from iron deficiency anemia has been associated with lower bone remodeling without significant change in 250HD level [14]. There are several differences between our study and similar trials that may justify our findings. These differences include the presence of iron deficiency in all participants and longer study duration. Additionally, in all of these studies, procollagen type I N-terminal propeptide was measured that is the most accurate marker of the formation [28]. However, $1,25(\mathrm{OH})_{2} \mathrm{D}_{3}$ induces mRNA, synthesis, and secretion of osteocalcin by human and rat bone cells in vitro which is sensitive and specific for the evaluation of formation in adults[37]. Unfortunately, none of these studies evaluated the effect of iron and vitamin D compared to vitamin $\mathrm{D}$ alone. Furthermore, we did not include a third group of iron-placebo in our trial. The increased bone turnover can be attributed to the coupling of formation and resorption. It has reported that serum osteocalcin is increased in patients with untreated osteomalacia [38]. So, it can be concluded that both groups experienced enhanced formation coupled with resorption. Additionally, calcium intake was less than recommended dietary intake in both groups. Low levels of calcium and phosphorus stimulate PTH secretion and consequent increased $1,25(\mathrm{OH})_{2} \mathrm{D}_{3}$ concentration[39]. Both hormones increase bone resorption to provide calcium and phosphorus required for calcification and this could be another reason for the lack of decreased bone turnover in this trial. Four months supplementation with 20,000 IU/w vitamin $\mathrm{D}$ in 399 subjects with mean baseline $250 \mathrm{HD} 34.0 \mathrm{nmol} / \mathrm{L}$ resulted in small, but significant reduction of procollagen of type 1 amino-terminal propeptide (P1NP), without any effect on CTX, Dickkopf-1, sclerostin, TNF-a, osteoprotegerin, and receptor activator of nuclear factor KB ligand [40]. Those with high baseline PTH who had a decrease in PTH after the intervention, experienced higher decrease of P1NP and also significant reduction of serum CTX and increased sclerostin. Authors concluded that vitamin D supplementation is not effective or may even exaggerate bone loss if not combined with sufficient calcium intake. It is also seen that the response of bone turnover markers is different to osteoporosis treatments [41]; anti-resorptive treatments, like bisphosphonates, cause an early bone resorption and a delayed bone formation 
decrease, while anabolic treatments such as teriparatide result in an initial increase of bone formation markers and subsequent increase of bone resorption. It seems that the action of vitamin D in our study was like an anabolic treatment.

Our study showed a significant increase of interleukin-6 in D-P group without any effect on in none of groups. Previous studies with vitamin D supplementation have shown conflicting results. A decline in CRP has been reported among patients in the intensive care unit after vitamin D supplementation [42], while supplementation with $100,000 \mathrm{IU} / \mathrm{d}$ vitamin $\mathrm{D}_{2}$ or $\mathrm{D}_{3}$ had no clinically meaningful effect on hsCRP level [43]. Monthly intake of $1.25 \mathrm{mg}$ vitamin D for two years could not change inflammatory indexes like hs-CRP, IL-6, IL-8, and IL-10 in 200 patients with osteoarthritis and vitamin D deficiency [44]. A meta-analysis on diabetic patients showed that vitamin D supplementation could reduce hs-CRP but not TNF-a and IL-6 [45]. The difference in the results of studies could be due to supplementation dosage, treatment period, and the population studied. Higher serum concentration of hsCRP at baseline is effective on the results of vitamin D interventions [46].

Furthermore, supplemental vitamin D has increased interferon-y and interleukin-10 in subjects that were vitamin D insufficient compared to sufficient healthy adults [47]. Perhaps lack of reduction of inflammatory markers in this study and similar studies is attributed to lower duration of intervention and recruiting healthy subjects; because most studies with positive results have been conducted in patients with inflammation [48]. Besides, observed increased interleukin-6 in the D-P group may be related to the lack of regulatory effect of vitamin D on some inflammatory markers, low concentrations of inflammatory markers at baseline, low dose of vitamin $D$, and a higher percentage of patients with vitamin D deficiency.

Antioxidant effects of vitamin D was first established by Wiseman in 1993 by the concept that vitamin $D_{3}$ and the active form; $1,25(\mathrm{OH})_{2} \mathrm{D}_{3}$ halted iron-dependent peroxidation of liposomal lipid [49]. Vitamin $D_{3}$ mega dose of $(200,000$ IU) increased total antioxidant capacity in vitamin D sufficient elderly women, and did not affect malondialdehyde [50]. After 12 weeks of consumption of vitamin $D_{3}$-fortified doogh compared to plain doogh, significant decrease of malondialdehyde and enhancement of glutathione and TAC were revealed [51]. Failing to show positive results in the present study may be related to differences in patients' genotype for vitamin D receptor, low-dose supplements required for reduction of lipid peroxidation, and insufficient time to impact on oxidative stress markers.

According to some observational studies on type 2 diabetes patients, vitamin D may have positive effects on glucose homeostasis [52, 53]. However, a systematic review found a weak correlation between vitamin D supplementation and descending fasting blood glucose and addressing insulin resistance challenge in patients with type 2 diabetes or impaired glucose tolerance; while no effect was seen in subjects with normal glucose tolerance [54]. In a recent systematic review and meta-analysis on 20 randomized clinical trials including 1,464 patients with diabetic nephropathy, vitamin D supplementation had no impact on glycemic control indexes [55]. There are also some unpredictable findings. Supplementation with 50,000 IU/w vitamin D for eight weeks in healthy adults $>65$ years resulted an increase in the number of people with insulin resistance from 13.2-36.8\% [56]. The mean homeostatic model assessment of insulin resistance also increased from $1.39 \pm 1.34$ to $5.27 \pm 3.72$. Also, in Cox proportional hazard regression model, in contrast to multivariable binary logistic regression model, in order to predict the association between serum 250HD level and the incidence of type 2 diabetes, a positive relationship was observed at the highest vitamin D quartile [57]. Here, an increase in FBS was revealed in our healthy young women that is inexplicable and should be evaluated in future studies. Short duration of the study and limited number of participants could cofound our results.

After the intervention a significant increase in TG and decrease in LDL was observed in the D-P group, while HDL increased significantly in the D-Fe group. In a meta-analysis (including 4 clinical trials, three of them with poor quality and high heterogeneity) to evaluate the effect of vitamin D supplementation on cardiometabolic risk factors in healthy adults, no significant effect was observed [58]. Some studies have reported a positive relationship between $250 \mathrm{HD}$ and serum lipids $[59,60]$. Ponda et al. observed that correcting vitamin D deficiency by administering 50,000 IU of vitamin D weekly during 8 weeks significantly increased LDL-cholesterol in vitamin D-deficient high cardiovascular-risk adults [61]. This controversy in results may be due to differences in study design, dose of vitamin, and participant's conditions. Furthermore, sufficient 250HD has been attributed to better physical health and healthy lifestyle [62]. Our participants' vitamin D insufficiency may be related to non-specific chronic diseases. Supplementation with 50 mg iron with 500 mg docosahexaenoic acid or placebo in 76 women suffering from iron deficiency anemia caused significant decrease of apoAl in the group receiving iron and placebo [63]. Because of no significant between-group differences and small number of studies evaluating iron effects on cardiovascular health, it seems too early for conclusion.

The lack of effect of iron on vitamin D activation can be related to one or more of the following reasons: (a): the length of follow-up in studies evaluating bone markers is usually longer than the duration of the present study; (b) the dose of iron was not sufficient for iron status improvement; and (c) as previously mentioned, cytochrome P450 contains iron; however, in an animal study conducted by Dhur et al., in 1989 to assess the effects of different degrees of iron deficiency on cytochrome P450 enzymes it was suggested that modification of irondependent enzymes may only happen after the third stage of iron deficiency [64]. A recent study in rats demonstrated negative effects of iron deficiency on renal 1a-hydroxylase activity and bone formation [65]. However, the authors concluded that the severity of iron deficiency anemia in their animal model is rare in human subjects. To the best of our knowledge, this is the first randomized, triple masked, clinical trial 
to assess the effect of vitamin D-iron co-supplementation, compared to vitamin D-placebo supplementation on bone health among healthy females. Strengths of the current study included the study methodology and adjustment of some confounding factors like physical activity level, sun exposure, age, and body composition. Further studies should be performed to explore in depth the effects of iron on vitamin $D$ function and bone health.

This has some limitations which have to be pointed out. Firstly, all women were healthy and all parameters were within normal limits. It was assumed that most of participants with low hemoglobin levels are iron deficient; however, ferritin measurement did not prove our assumption and other reasons that can cause anemia may also affect the results of the present study. This study should have been performed in those with ferritin levels less than $30 \mathrm{ng} / \mathrm{ml}$. Furthermore, we were not able to measure blood levels of $250 \mathrm{HD}$ using liquid chromatography-mass spectrometry method. Another limitation is that we did no evaluate some demographic data such as socioeconomic status which could affect our results. We also did not assess factors like socioeconomic status which could affect our results. Finally, the present study was not statistically powerful enough to detect a difference between two groups in the primary outcome, 25OHD ( 23\%).

\section{Conclusions}

To sum up, we could not show additional effects of iron plus vitamin D intake on bone turnover, inflammatory, oxidative stress, and metabolic markers. Unwanted significant increases of some metabolic and inflammatory biomarkers show a special need for conducting further studies regarding the effects of iron and vitamin $D$ in individuals with concurrent vitamin d deficiency and iron deficiency anemia.

\section{Declarations}

\section{Acknowledgements}

We thank the participants for their cooperation and participation in this study.

\section{Authors' contributions}

FA-Z and MV designed this study. BA, FA-Z and HS participated in the conduct of the study. MS and FZ analyzed the data. BA, FA-Z, MS and HS drafted the manuscript. MV and SMK critically revised the manuscript. All authors read and approved the final manuscript.

\section{Funding}

This work was financially supported by the Vice Chancellor of Research, Iran University of Medical Sciences.

\section{Availability of data and materials}

The data can be made available on reasonable request to the corresponding author.

\section{Ethics approval and consent to participate}

Written informed consent was obtained from all participants on recruitment. The protocol of this study was approved by the Medical Ethics Committee of Iran University of Medical Sciences, is in conformity with the Declaration of Helsinki (approval number: 94-02-27-25971) and was registered at the Iranian Registry of Clinical Trials (IRCT registration number: IRCT201409082365N9) which is available at: http://irct.ir/user/trial/20288/view.

\section{Consent for publication}

All authors have given consent for the paper to be published by the corresponding author.

\section{Competing interest}

The authors declare that they have no conflict of interest.

\section{Author details}


${ }^{1}$ Department of Nutrition, Faculty of Paramedicine, Ahvaz Jundishapur University of Medical Sciences, Ahvaz, Iran. ${ }^{2}$ Department of Clinical Nutrition, School of Nutrition \& Food Science, Isfahan University of Medical Sciences, Isfahan, Iran. ${ }^{3}$ Department of Nutrition, School of Public Health, Iran University of Medical Sciences, Tehran, 1449614535, Iran. ${ }^{4}$ Bone, Joint, and Related Tissue Research Center, Akhtar Hospital, Shahid Beheshti University of Medical Sciences, Tehran, Iran. ${ }^{5}$ Department of Biostatistics, School of Public Health, Iran University of Medical Sciences, Tehran, Iran. ${ }^{6}$ Department of Biostatistics, Faculty of Paramedical Sciences, Shahid Beheshti University of Medical Sciences, Tehran, Iran. ${ }^{7}$ School of Public Health, Department of Nutrition and Food Science, Texas Woman's University, TX 76204, Denton Campus.

\section{References}

1. Holick MF (2007) Vitamin D deficiency. N Engl J Med 357 (3):266-281. doi:10.1056/NEJMra070553

2. McLean E, Cogswell M, Egli I, Wojdyla D, de Benoist B (2009) Worldwide prevalence of anaemia, WHO Vitamin and Mineral Nutrition Information System, 1993-2005. Public Health Nutr 12 (4):444-454. doi:10.1017/s1368980008002401

3. Grober U, Spitz J, Reichrath J, Kisters K, Holick M (2013) Vitamin D: update 2013: from rickets prophylaxis to general preventive healthcare. Dermatoendocrinol 5 (3):331-347

4. Wang L-X, Wang N, Xu Q-L, Yan W, Dong L, Li B-L (2017) Effects of vitamin D combined with pioglitazone hydrochloride on bone mineral density and bone metabolism in Type 2 diabetic nephropathy. Biosci Rep 37 (2):BSR20160544

5. Lang C-L, Wang M-H, Chiang C-K, Lu K-C (2014) Vitamin D and the Immune System from the Nephrologist's Viewpoint. ISRN endocrinology 2014

6. Nair-Shalliker V, Armstrong BK, Fenech M (2012) Does vitamin D protect against DNA damage? Mutation Research/Fundamental and Molecular Mechanisms of Mutagenesis 733 (1):50-57

7. Wang C (2013) Role of vitamin d in cardiometabolic diseases. Experimental Diabetes Research 2013

8. vinh quoc Lu'o'ng K, Nguyen LT (2013) The beneficial role of vitamin D in obesity: possible genetic and cell signaling mechanisms. Nutr J 12:89. doi:10.1186/1475-2891-12-89

9. Lawson M, Thomas M (1999) Vitamin D concentrations in Asian children aged 2 years living in England: population survey. BMJ 318 (7175):28

10. Grindulis H, Scott PH, Belton NR, Wharton BA (1986) Combined deficiency of iron and vitamin D in Asian toddlers. Arch Dis Child 61 (9):843-848

11. Azizi-Soleiman F, Vafa M, Abiri B, Safavi M (2016) Effects of iron on Vitamin D metabolism: A systematic review. Int J Prev Med 7

12. Bikle DD (2014) Vitamin D Metabolism, Mechanism of Action, and Clinical Applications. Chem Biol 21 (3):319-329. doi:10.1016/j.chembiol.2013.12.016

13. Heldenberg D, Tenenbaum G, Weisman Y (1992) Effect of iron on serum 25-hydroxyvitamin D and 24,25-dihydroxyvitamin D concentrations. Am J Clin Nutr 56 (3):533-536

14. Wright I, Blanco-Rojo R, Fernández MC, Toxqui L, Moreno G, Pérez-Granados AM, de la Piedra C, Remacha ÁF, Vaquero MP (2013) Bone remodelling is reduced by recovery from iron-deficiency anaemia in premenopausal women. J Physiol Biochem 69 (4):889-896

15. Balogh E, Paragh G, Jeney V (2018) Influence of Iron on Bone Homeostasis. Pharmaceuticals (Basel) 11 (4). doi:10.3390/ph11040107

16. Ilich-Ernst JZ, McKenna AA, Badenhop NE, Clairmont AC, Andon MB, Nahhas RW, Goel P, Matkovic V (1998) Iron status, menarche, and calcium supplementation in adolescent girls. The American journal of clinical nutrition 68 (4):880-887

17. Beutler E, Waalen J (2006) The definition of anemia: what is the lower limit of normal of the blood hemoglobin concentration? Blood 107 (5):1747-1750

18. Dallman P, Siimes MA, Stekel A (1980) Iron deficiency in infancy and childhood. Am J Clin Nutr 33 (1):86-118

19. Holick MF, Chen TC (2008) Vitamin D deficiency: a worldwide problem with health consequences. Am J Clin Nutr 87 (4):1080S-1086S

20. Heaney RP, Davies KM, Chen TC, Holick MF, Barger-Lux MJ (2003) Human serum 25-hydroxycholecalciferol response to extended oral dosing with cholecalciferol. The American journal of clinical nutrition 77 (1):204-210

21. Moghaddam MHB, Aghdam FB, Jafarabadi MA, Allahverdipour H, Nikookheslat SD, Safarpour S (2012) The Iranian Version of International Physical Activity Questionnaire (IPAQ) in Iran: content and construct validity, factor structure, internal consistency and stability. World Appl Sci 18 (8):1073-1080

22. Nikooyeh B, Abdollahi Z, Hajifaraji M, Alavi-Majd H, Salehi F, Yarparvar AH, Neyestani TR (2016) Vitamin D Status, Latitude and their Associations with Some Health Parameters in Children: National Food and Nutrition Surveillance. J Trop Pediatr:fmw057 
23. Abioye Al, Aboud S, Premji Z, Etheredge AJ, Gunaratna NS, Sudfeld CR, Mongi R, Meloney L, Darling AM, Noor RA (2016) Iron Supplementation Affects Hematologic Biomarker Concentrations and Pregnancy Outcomes among Iron-Deficient Tanzanian Women. The Journal of nutrition:jn225482

24. Mielgo-Ayuso J, Zourdos MC, Calleja-Gonzalez J, Urdampilleta A, Ostojic S (2015) Iron supplementation prevents a decline in iron stores and enhances strength performance in elite female volleyball players during the competitive season. Appl Physiol Nutr Metab 40

(6):615-622. doi:10.1139/apnm-2014-0500

25. Hennigar SR, Gaffney-Stomberg E, Lutz LJ, Cable SJ, Pasiakos SM, Young AJ, McClung JP (2016) Consumption of a calcium and vitamin D-fortified food product does not affect iron status during initial military training: a randomised, double-blind, placebo-controlled trial. Br J Nutr 115 (4):637-643

26. Harvey LJ, Armah CN, Dainty JR, Foxall RJ, Lewis DJ, Langford NJ, Fairweather-Tait SJJBJoN (2005) Impact of menstrual blood loss and diet on iron deficiency among women in the UK. 94 (4):557-564

27. Camaschella CJNEjom (2015) Iron-deficiency anemia. 372 (19):1832-1843

28. Feldman D, Pike JW, Adams JS (2011) Vitamin D

29. Wamberg L, Pedersen SB, Richelsen B, Rejnmark L (2013) The effect of high-dose vitamin D supplementation on calciotropic hormones and bone mineral density in obese subjects with low levels of circulating 25-hydroxyvitamin d: results from a randomized controlled study. Calcif Tissue Int 93 (1):69-77. doi:10.1007/s00223-013-9729-3

30. Nahas-Neto J, Cangussu L, Orsatti C, Bueloni-Dias F, Poloni P, Schmitt E, Nahas E (2018) Effect of isolated vitamin D supplementation on bone turnover markers in younger postmenopausal women: a randomized, double-blind, placebo-controlled trial. Osteoporos Int 29 (5):1125-1133

31. Lerchbaum E, Trummer C, Theiler-Schwetz V, Kollmann M, Wölfler M, Pilz S, Obermayer-Pietsch BJN (2019) Effects of Vitamin D Supplementation on Bone Turnover and Bone Mineral Density in Healthy Men: A Post-Hoc Analysis of a Randomized Controlled Trial. 11 (4):731

32. Callegari ET, Garland SM, Gorelik A, Chiang CY, Wark JD (2018) Bone turnover marker determinants in young women: results from the Safe-D study. Ann Clin Biochem 55 (3):328-340

33. Blanco-Rojo R, Perez-Granados AM, Toxqui L, Zazo P, de la Piedra C, Vaquero MP (2013) Relationship between vitamin D deficiency, bone remodelling and iron status in iron-deficient young women consuming an iron-fortified food. Eur J Nutr 52 (2):695-703. doi:10.1007/s00394-012-0375-8

34. Diaz-Castro J, Lopez-Frias MR, Campos MS, Lopez-Frias M, Alferez MJ, Nestares T, Ojeda ML, Lopez-Aliaga I (2012) Severe nutritional iron-deficiency anaemia has a negative effect on some bone turnover biomarkers in rats. Eur J Nutr 51 (2):241-247. doi:10.1007/s00394-011-0212-5

35. Toxqui L, Perez-Granados AM, Blanco-Rojo R, Wright I, de la Piedra C, Vaquero MP (2014) Low iron status as a factor of increased bone resorption and effects of an iron and vitamin D-fortified skimmed milk on bone remodelling in young Spanish women. Eur $\mathrm{J}$ Nutr 53 (2):441-448. doi:10.1007/s00394-013-0544-4

36. Fuzi SFA, Mushtaq S (2019) Vitamin D 3 supplementation for 8 weeks leads to improved haematological status following the consumption of an iron-fortified breakfast cereal: a double-blind randomised controlled trial in iron-deficient women. $\mathrm{Br} \mathrm{J} \mathrm{Nutr} 121$ (10):1146-1157

37. Holick MF (2010) Vitamin D : physiology, molecular biology, and clinical applications. Nutrition and health, vol 7659, 2nd edn. Humana Press, New York

38. Demiaux B, Arlot ME, Chapuy MC, Meunier PJ, Delmas PD (1992) Serum osteocalcin is increased in patients with osteomalacia: correlations with biochemical and histomorphometric findings. J Clin Endocrinol Metab 74 (5):1146-1151. doi:10.1210/jcem.74.5.1569162

39. Moe SM (2008) Disorders involving calcium, phosphorus, and magnesium. Prim Care 35 (2):215-237

40. Jorde R, Stunes AK, Kubiak J, Joakimsen R, Grimnes G, Thorsby PM, Syversen UJB (2019) Effects of vitamin D supplementation on bone turnover markers and other bone-related substances in subjects with vitamin D deficiency. 124:7-13

41. Vasikaran S, Eastell R, Bruyère O, Foldes A, Garnero P, Griesmacher A, McClung M, Morris H, Silverman S, Trenti T (2011) Markers of bone turnover for the prediction of fracture risk and monitoring of osteoporosis treatment: a need for international reference standards. Osteoporos Int 22 (2):391-420

42. Van den Berghe G, Van Roosbroeck D, Vanhove P, Wouters PJ, De Pourcq L, Bouillon R (2003) Bone turnover in prolonged critical illness: effect of vitamin D. The Journal of Clinical Endocrinology \& Metabolism 88 (10):4623-4632 
43. Forouhi N, Menon R, Sharp S, Mannan N, Timms P, Martineau A, Rickard A, Boucher B, Chowdhury T, Griffiths C (2016) Effects of vitamin D2 or D3 supplementation on glycaemic control and cardiometabolic risk among people at risk of type 2 diabetes: results of a randomized double-blind placebo-controlled trial. Diabetes, Obesity and Metabolism

44. Zheng S, Wang B, Han W, Zhu Z, Wang X, Jin X, Antony B, Cicuttini F, Wluka A, Winzenberg T, Aitken D, Blizzard L, Jones G, Ding C (2018) Vitamin $\mathrm{D}$ supplementation and inflammatory and metabolic biomarkers in patients with knee osteoarthritis: post hoc analysis of a randomised controlled trial. Br J Nutr 120 (1):41-48. doi:10.1017/s0007114518001174

45. Yu Y, Tian L, Xiao Y, Huang G, Zhang MJAoN, Metabolism (2018) Effect of vitamin D supplementation on some inflammatory biomarkers in type 2 diabetes mellitus subjects: a systematic review and meta-analysis of randomized controlled trials. 73:62-73

46. Chen N, Wan Z, Han S-F, Li B-Y, Zhang Z-L, Qin L-Q (2014) Effect of vitamin D supplementation on the level of circulating high-sensitivity C-reactive protein: a meta-analysis of randomized controlled trials. Nutrients 6 (6):2206-2216

47. Barker T, Rogers VE, Levy M, Templeton J, Goldfine H, Schneider ED, Dixon BM, Henriksen VT, Weaver LK (2015) Supplemental vitamin D increases serum cytokines in those with initially low 25-hydroxyvitamin D: a randomized, double blind, placebo-controlled study. Cytokine 71 (2):132-138

48. Al-Jurayyan NA, Al Jurayyan AN, Al Omran HI, Al Jurayyan RN, Al Jurayyan AN, Babiker AM (2015) Alkaline Phosphatase (ALP) Activity as a marker for Vitamin D deficiency. Am J Res Com

49. Wiseman H (1993) Vitamin D is a membrane antioxidant Ability to inhibit iron-dependent lipid peroxidation in liposomes compared to cholesterol, ergosterol and tamoxifen and relevance to anticancer action. FEBS Lett 326 (1-3):285-288

50. Cavalcante IG, Silva AS, Costa MJ, Persuhn DC, Issa CI, Freire TL, Goncalves MD (2015) Effect of vitamin D3 supplementation and influence of Bsml polymorphism of the VDR gene of the inflammatory profile and oxidative stress in elderly women with vitamin D insufficiency: Vitamin D3 megadose reduces inflammatory markers. Exp Gerontol 66:10-16. doi:10.1016/j.exger.2015.03.011

51. Shab-Bidar S, Neyestani TR, Djazayery A (2015) The interactive effect of improvement of vitamin D status and VDR Fokl variants on oxidative stress in type 2 diabetic subjects: a randomized controlled trial. Eur J Clin Nutr 69 (2):216-222. doi:10.1038/ejcn.2014.240

52. Pittas AG, Lau J, Hu FB, Dawson-Hughes B (2007) The role of vitamin D and calcium in type 2 diabetes. A systematic review and metaanalysis. The Journal of Clinical Endocrinology \& Metabolism 92 (6):2017-2029

53. Christakos S, Hewison M, Gardner DG, Wagner CL, Sergeev IN, Rutten E, Pittas AG, Boland R, Ferrucci L, Bikle DD (2013) Vitamin D: beyond bone. Annals of the New York Academy of Sciences 1287 (1):45-58

54. George P, Pearson E, Witham M (2012) Effect of vitamin D supplementation on glycaemic control and insulin resistance: a systematic review and meta-analysis. Diabetic Medicine 29 (8)

55. Wang Y, Yang S, Zhou Q, Zhang H, Yi BJK, Research BP (2019) Effects of Vitamin D Supplementation on Renal Function, Inflammation and Glycemic Control in Patients with Diabetic Nephropathy: a Systematic Review and Meta-Analysis. 44 (1):72-87

56. Kaviani M, Abdollahian M, Almasi V, Amini M, Yamini AA (2012) Effects of vitamin D on insulin resistance in nursing home residents: an interventional study. Endokrynol Pol 63 (3):191-195

57. Li H-w, 畈 (2015) The role of vitamin D in type 2 diabetes risk: a retrospective study. HKU Theses Online (HKUTO)

58. Pittas AG, Chung M, Trikalinos T, Mitri J, Brendel M, Patel K, Lichtenstein AH, Lau J, Balk EM (2010) Systematic review: Vitamin D and cardiometabolic outcomes. Ann Intern Med 152 (5):307-314

59. Giovannucci E, Liu Y, Hollis BW, Rimm EB (2008) 25-hydroxyvitamin D and risk of myocardial infarction in men: a prospective study. Archives of internal medicine 168 (11):1174-1180

60. Delvin EE, Lambert M, Levy E, O'loughlin J, Mark S, Gray-Donald K, Paradis G (2010) Vitamin D status is modestly associated with glycemia and indicators of lipid metabolism in French-Canadian children and adolescents. The Journal of nutrition 140 (5):987-991

61. Ponda MP, Dowd K, Finkielstein D, Holt PR, Breslow JL (2012) The Short-Term Effects of Vitamin D Repletion on Cholesterol. Arteriosclerosis, thrombosis, and vascular biology 32 (10):2510-2515

62. Tønnesen R, Hovind PH, Jensen LT, Schwarz P (2016) Determinants of vitamin D status in young adults: influence of lifestyle, sociodemographic and anthropometric factors. BMC public health 16 (1):385

63. Shidfar F, Amani S, Vafa M, Shekarriz R, Hosseini S, Shidfar S, Eshraghian M, Mousavi SN (2016) Effects of Iron Supplementation With and Without Docosahexaenoic Acid on the Cardiovascular Disease Risk Based on Paraoxonase-1, hs-CRP, and ApoB/ApoA-I Ratio in Women with Iron Deficiency Anemia. Biol Trace Elem Res 169 (1):34-40

64. DHÃœR A, HERCBERG PGAS (1989) Effects of different degrees of iron deficiency on cytochrome P450 complex and pentose phosphate pathway dehydrogenases in the rat.

65. Katsumata S, Katsumata R, Matsumoto N, Inoue H, Takahashi N, Uehara M (2016) Iron deficiency decreases renal 25-hydroxyvitamin D 3-1a-hydroxylase activity and bone formation in rats. BMC Nutrition 2 (1):33

Page 10/15 


\section{Tables}

1. Characteristics of the participants at baseline according to randomly assigned group

\begin{tabular}{lcccc}
\hline & All $(\mathbf{n}=\mathbf{1 0 0})$ & D-Fe $(\mathbf{n}=50)$ & D-P $(\mathbf{n}=50)$ & P-value \\
year & $34.6 \pm 7.4$ & $34.1 \pm 7.6$ & $35.2 \pm 6.7$ & $0.094^{*}$ \\
ied, $\mathrm{n}(\%)$ & $62(62.0)$ & $30(62.0)$ & $32(64.0)$ & $0.267^{*}$ \\
'weight, $\mathrm{kg}$ & $70.2 \pm 14.5$ & $70.7 \pm 14.9$ & $69.7 \pm 14.1$ & $0.714^{*}$ \\
$\mathrm{~kg} / \mathrm{m}^{2}$ & $27.2 \pm 1.2$ & $26.6 \pm 1.2$ & $27.8 \pm 1.2$ & $0.304^{*}$ \\
ical activity level, MET/hour & $1459.1 \pm 2946.6$ & $1430.7 \pm 2062.2$ & $1484.9 \pm 3591.0$ & $0.892^{*}$ \\
\hline
\end{tabular}

are expressed as mean \pm SD except for marriage status

ained from Independent Samples T-test

body mass index, MET: metabolic equivalent 
Table 2. The effects of vitamin D-placebo vs. vitamin D-iron co-supplementation on the hematologic, bone turnover, inflammatory, oxidative stress and metabolic biomarkers

D-placebo $(\mathrm{n}=39)$

RBC, $\times 1012 / \mathrm{L}$

$\mathrm{Hb}, \mathrm{g} / \mathrm{dL}$

Hct, \%

MCV, fL

$\mathrm{MCH}, \mathrm{pg}$

MCHC, $g / d L$

Ferritin, ng/mL

Serum Fe, $\mu \mathrm{g} / \mathrm{dL}$

Transferrin,

$\mathrm{mg} / \mathrm{dL}$

Transfer

$20.4 \pm 17.4$

Saturation, \%

TIBC, $\mu \mathrm{mol} / \mathrm{L}$

25OHD, ng/mL

ALPEM, ng/mL

ALPEA, IU/L

Osteocalcin

$\mathrm{ng} / \mathrm{mL}$

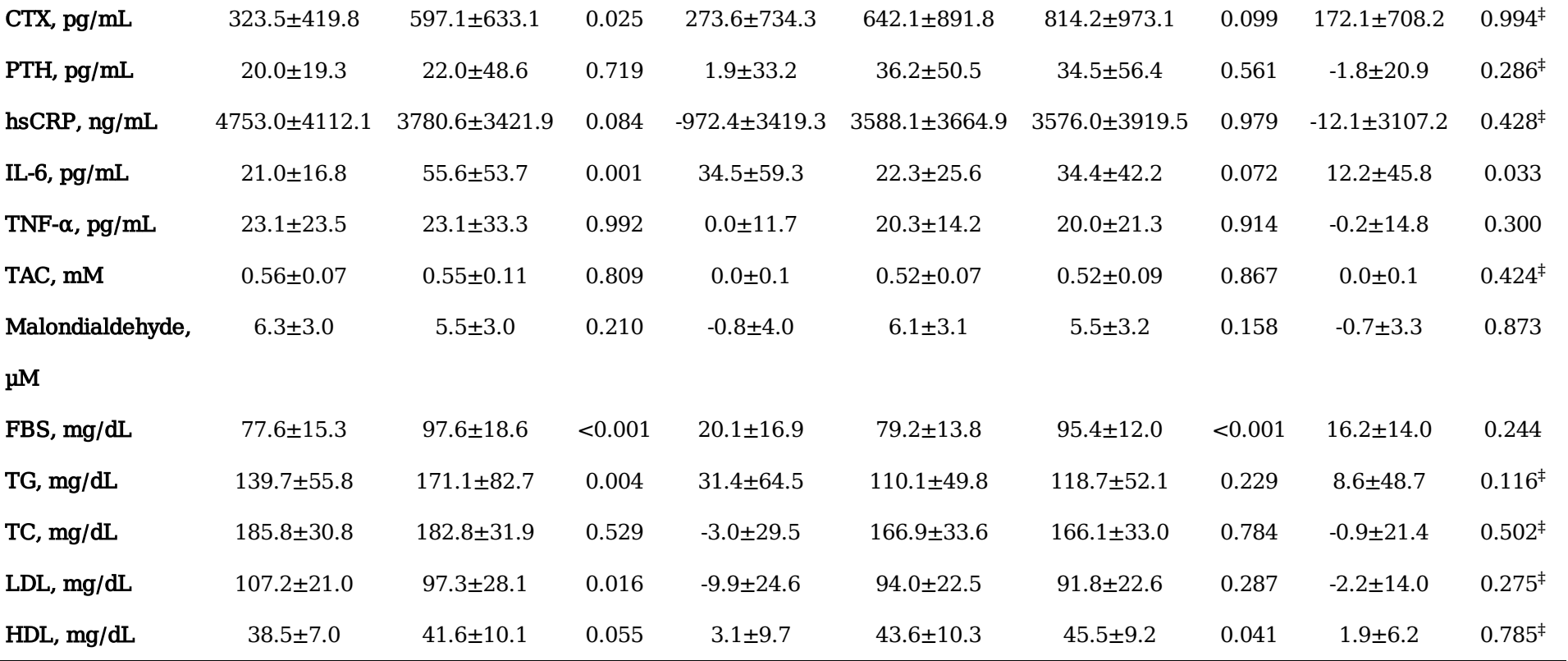

*P-value for between group changes, obtained from Mann-Whitney or Independent Samples T-test

†P-value for within group changes, obtained from Paired Samples T-tests or Wilcoxon Signed Ranks test

Data are presented as mean \pm SD

$\mathrm{D}-\mathrm{Fe}(\mathrm{n}=48)$

P-

value*

P-
value $^{\dagger}$

Mean change

Baseline

Week 12

Mean

value $^{\dagger} \quad$ change

$4.7 \pm 0.5<0.001$

$-0.4 \pm 0.3$

4.8 \pm 0.6

$4.6 \pm 0.5$

0.001

$-0.2 \pm 0.3$

$0.005^{\ddagger}$

$10.6 \pm 1.0<0.001 \quad-1.5 \pm 0.9$

$12.3 \pm 1.0$

$12.0 \pm 1.2$

0.204

$-0.2 \pm 1.2<0.001$

$38.4 \pm 2.6$

$37.1 \pm 2.7$

0.004

$-1.3 \pm 3.0$

$<0.001$

$74.7 \pm 10.2 \quad 0.004$

$-1.7 \pm 3.5$

$81.4 \pm 7.8$

81.2 \pm 7.6

0.782

$-0.1 \pm 3.3$

$0.038^{\ddagger}$

$22.9 \pm 3.5<0.001$

$-1.1 \pm 1.2$

$26.3 \pm 2.9$

0.102

$0.4 \pm 1.5$

$<0.001^{\ddagger}$

$30.7 \pm 1.4$

$-0.6 \pm 1.3$

$31.8 \pm 1.2$

$32.4 \pm 1.3$

0.001

$0.5 \pm 1.0$

$<0.001$

$43.0 \pm 43.1$

$43.1 \pm 34.3$

0.989

$0.0 \pm 23.9$

$0.004^{\ddagger}$

$50.6 \pm 37.5$

0.151

$-11.7 \pm 49.9$

$59.6 \pm 41.0$

$68.1 \pm 37.4$

0.217

$8.5 \pm 46.9$

0.018

$306 \pm 96.9$

$290.3 \pm 87.8$

0.363

$-15.7 \pm 118.3$

0.542

$17.2 \pm 14$.

0.311

$-3.2 \pm 19.3$

$18.1 \pm 14.1$

$20.9 \pm 12.3$

0.197

$2.8 \pm 14.9$

0.088

$326.7 \pm 99.9 \quad 0.087$

$-38.5 \pm 136.7$

$382.4 \pm 121$.

$362.9 \pm 109.7$

0.364

$-19.6 \pm 147.9$

0.542

$41.7 \pm 17.2<0.001 \quad 21.0 \pm 14.4$

$19.2 \pm 8.1$

$44.0 \pm 15.8$

$<0.001$

$24.8 \pm 14.6$

0.239

$9.4 \pm 21.1$

0.334

$2.8 \pm 17.7$

$12.9 \pm 19.0$

$12.8 \pm 21.5$

0.980

$0.0 \pm 8.2$

$0.198^{\ddagger}$

$128.5 \pm 18.7 \quad 0.327$

$2.5 \pm 15.6$

$131.5 \pm 16.7$

$131.5 \pm 19.0$

0.968

$0.0 \pm 7.3$

$0.187^{\ddagger}$

$29.6 \pm 24.8<0.001$

$15.2 \pm 11.7$

$17.7 \pm 21.7$

$26.2+25.8$

$<0.001$

$8.5+13.4$

0.007

CTX, pg/m

$3.5 \pm 419$ 
RBC: red blood cell, Hb: hemoglobin, Hct: hematocrit, MCV: mean corpuscular volume, MCH: mean corpuscular hemoglobin, MCHC: mean cell hemoglobin concentration, TIBC: total iron binding capacity, ALPEM: alkaline phosphatase enzyme mass, ALPEA: alkaline phosphatase enzyme activity, CTX: C-terminal telopeptide, PTH: parathyroid hormone, hsCRP: highly-sensitive C-reactive protein, IL-6: interleukin-6,TNF- $\alpha$ : tumor necrosis factor- $\alpha$, TAC: total antioxidant capacity, malondialdehyde: malondialdehyde, FBS: fasting blood sugar, TG: triglyceride, TC: total cholesterol, LDL: low density cholesterol, HDL: high density cholesterol

ble 3. Habitual dietary intake of participants at baseline and after 12 weeks Variables

$$
\text { Groups }
$$

\begin{tabular}{|c|c|c|c|}
\hline & \multirow{2}{*}{\multicolumn{2}{|c|}{ D-Fe (Mean \pm SD) $\quad$ D-P $($ Mean \pm SD) }} \\
\hline & & & \\
\hline \multirow[t]{3}{*}{ iergy, kcal/d } & Before & $1786.3 \pm 544.9$ & $1837.2 \pm 498.4$ \\
\hline & After & $1741.6 \pm 382.6$ & $1743.7 \pm 566.9$ \\
\hline & $P$ Value* & 0.955 & 0.706 \\
\hline \multirow[t]{3}{*}{ arbohydrate, g/d } & Before & $234.7 \pm 61.6$ & $236.3 \pm 52.1$ \\
\hline & After & $234.1 \pm 58.3$ & $226.7 \pm 61.3$ \\
\hline & $P$ Value ${ }^{*}$ & 0.759 & 0.500 \\
\hline \multirow[t]{3}{*}{ otein, $\mathrm{g} / \mathrm{d}$} & Before & $58.7 \pm 20.8$ & $57.9 \pm 18.2$ \\
\hline & After & $57.1 \pm 12.6$ & $58.5 \pm 14.1$ \\
\hline & $P$ Value ${ }^{*}$ & 0.860 & 0.695 \\
\hline \multirow[t]{3}{*}{ it, $g / d$} & Before & $75.8 \pm 37.8$ & $78.7 \pm 34.7$ \\
\hline & After & $65.7 \pm 30.7$ & $74.2 \pm 39.3$ \\
\hline & $P$ Value ${ }^{*}$ & 0.283 & 0.413 \\
\hline \multirow[t]{3}{*}{ 1olesterol, mg/d } & Before & $142.6 \pm 1.9$ & $172.7 \pm 2.2$ \\
\hline & After & $138.8 \pm 2.0$ & $141.3 \pm 2.2$ \\
\hline & $P$ Value ${ }^{*}$ & 0.837 & 0.273 \\
\hline \multirow[t]{3}{*}{ etary fiber, $\mathrm{g} / \mathrm{d}$} & Before & $10.8 \pm 1.8$ & $9.7 \pm 1.6$ \\
\hline & After & $15.1 \pm 1.4$ & $11.6 \pm 1.5$ \\
\hline & $P$ Value* & 0.087 & 0.094 \\
\hline \multirow[t]{3}{*}{ agnesium, mg/d } & Before & $206.9 \pm 97.0$ & $205.4 \pm 99.6$ \\
\hline & After & $195.7 \pm 73.7$ & $192.2 \pm 77.4$ \\
\hline & $P$ Value* & 0.834 & 0.850 \\
\hline \multirow[t]{3}{*}{ 10sphorous, mg/d } & Before & $840.4 \pm 363.1$ & $810.3 \pm 340.5$ \\
\hline & After & $848.6 \pm 310.4$ & $845.8 \pm 291.5$ \\
\hline & $P$ Value ${ }^{*}$ & 0.706 & 0.557 \\
\hline \multirow[t]{3}{*}{ כn, mg/d } & Before & $12.7 \pm 4.3$ & $14.1 \pm 5.3$ \\
\hline & After & $12.0 \pm 3.9$ & $11.68 \pm 4.7$ \\
\hline & $P$ Value* & 0.706 & 0.184 \\
\hline \multirow[t]{3}{*}{ lcium, mg/d } & Before & $538.7 \pm 319.2$ & $595.7 \pm 272.5$ \\
\hline & After & $584.6 \pm 217.3$ & $613.4 \pm 282.5$ \\
\hline & $P$ Value ${ }^{*}$ & 0.209 & 0.902 \\
\hline \multirow[t]{3}{*}{ lenium, $\mathrm{mg} / \mathrm{d}$} & Before & $0.10 \pm 0.06$ & $0.10 \pm 0.05$ \\
\hline & After & $0.13 \pm 0.10$ & $0.13 \pm 0.03$ \\
\hline & $P$ Value ${ }^{*}$ & 0.325 & 0.629 \\
\hline \multirow[t]{3}{*}{$\operatorname{tamin} \mathbf{K}, \mu \mathrm{g} / \mathrm{d}$} & Before & $102.8 \pm 122.2$ & $103.8 \pm 156.8$ \\
\hline & After & $112.7 \pm 133.7$ & $97.5 \pm 100.9$ \\
\hline & $P$ Value ${ }^{*}$ & 0.727 & 0.482 \\
\hline \multirow[t]{3}{*}{$\operatorname{tamin} \mathrm{D}, \mu \mathrm{g} / \mathrm{d}$} & Before & $0.9 \pm 1.1$ & $1.2 \pm 1.6$ \\
\hline & After & $0.9 \pm 1.3$ & $1.0 \pm 1.4$ \\
\hline & $P$ Value ${ }^{*}$ & 0.28 & 0.91 \\
\hline \multirow[t]{3}{*}{$\operatorname{tamin} \mathrm{E}, \mathrm{mg} / \mathrm{d}$} & Before & $4.0 \pm 2.9$ & $6.4 \pm 4.5$ \\
\hline & After & $3.6 \pm 3.3$ & $8.5 \pm 5.9$ \\
\hline & $P$ Value ${ }^{*}$ & 0.082 & 0.112 \\
\hline \multirow[t]{3}{*}{$\operatorname{tamin} \mathrm{C}, \mathrm{mg} / \mathrm{d}$} & Before & $44.2 \pm 2.9$ & $47.2 \pm 2.4$ \\
\hline & After & $62.3 \pm 2.1$ & $61.8 \pm 2.2$ \\
\hline & $P$ Value ${ }^{*}$ & 0.085 & 0.161 \\
\hline
\end{tabular}

ibtained from Paired Samples T-test \& Wilcoxon Signed Ranks Test 
Table 4. Sun exposure of participants at baseline and after 12 weeks

\begin{tabular}{|c|c|c|c|c|c|}
\hline \multirow[t]{2}{*}{ Variables } & & & \multicolumn{2}{|c|}{ Groups } & \multirow[t]{2}{*}{ P Value } \\
\hline & & & $\mathrm{D}-\mathrm{Fe}[\mathrm{n}(\%)]$ & D-P [n (\%)] & \\
\hline \multirow{4}{*}{ Sun exposure duration } & $<1 \mathrm{hr} / \mathrm{d}$ & Before $^{*}$ & $35(85.3)$ & $32(84.2)$ & 0.526 \\
\hline & & After ${ }^{* *}$ & $37(90.2)$ & $30(78.9)$ & \\
\hline & $>1 \mathrm{hr} / \mathrm{d}$ & Before* & $6(14.7)$ & $6(15.8)$ & \\
\hline & & After ${ }^{* *}$ & $4(9.8)$ & $8(21.1)$ & \\
\hline \multirow[t]{4}{*}{ Time of sun exposure } & 10am-3pm & Before $^{*}$ & $28(68.2)$ & $23(60.5)$ & 0.099 \\
\hline & & After $^{* *}$ & $26(63.4)$ & $22(57.8)$ & \\
\hline & Other times & Before* & 13(31.8) & $15(39.5)$ & \\
\hline & & After ${ }^{* *}$ & 15(36.6) & $16(42.2)$ & \\
\hline \multirow[t]{8}{*}{ Sun exposure area } & Face & Before* $^{*}$ & $14(34.2)$ & $15(39.4)$ & 0.264 \\
\hline & & After ${ }^{* *}$ & $16(39.0)$ & $17(44.7)$ & \\
\hline & Hands & Before* $^{*}$ & $5(12.2)$ & $1(2.6)$ & \\
\hline & & After ${ }^{* *}$ & $4(9.7)$ & $1(2.6)$ & \\
\hline & Face and hands & Before* & $17(41.5)$ & $18(47.5)$ & \\
\hline & & After $^{* *}$ & $15(36.6)$ & $16(42.2)$ & \\
\hline & Other areas & Before* & $5(12.1)$ & $4(10.5)$ & \\
\hline & & After $^{* *}$ & $6(14.7)$ & $4(10.5)$ & \\
\hline \multirow[t]{4}{*}{ Sun screen use } & Sometimes & Before $^{*}$ & $34(82.9)$ & $31(81.6)$ & 0.670 \\
\hline & & After ${ }^{* *}$ & $35(85.3)$ & $31(81.6)$ & \\
\hline & Always & Before* & $7(17.1)$ & $7(18.4)$ & \\
\hline & & After $^{* *}$ & $6(14.7)$ & $7(18.4)$ & \\
\hline \multirow[t]{4}{*}{ SPF of sunscreen } & $<50$ & Before $^{*}$ & $34(82.9)$ & $35(92.1)$ & 0.322 \\
\hline & & After $^{* *}$ & $35(85.3)$ & $36(94.7)$ & \\
\hline & $\geq 50$ & Before* & $7(17.1)$ & $3(7.9)$ & \\
\hline & & After $^{* *}$ & $6(14.7)$ & $2(5.3)$ & \\
\hline
\end{tabular}

${ }^{*}$ Obtained from chi-squared test

SPF: Sun protection factor

Figures

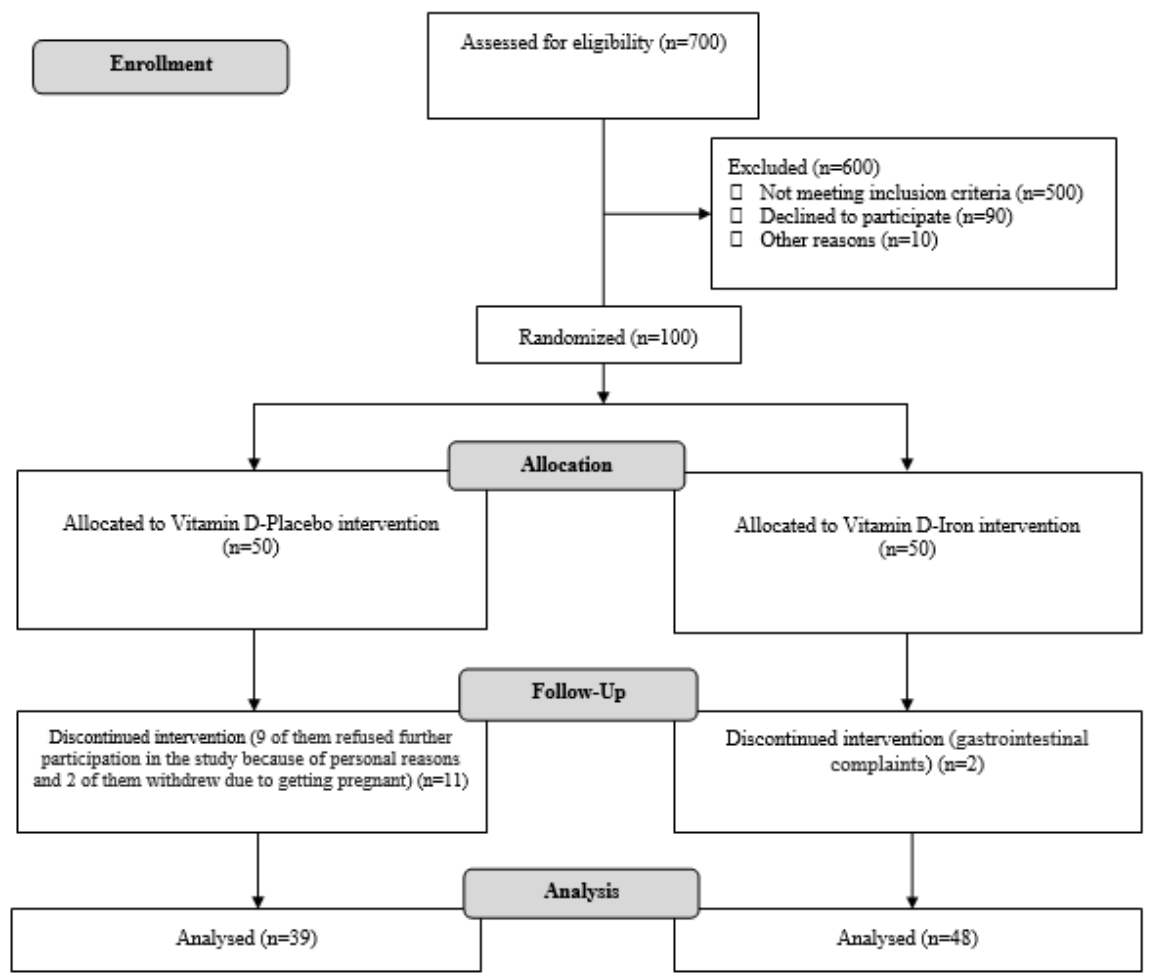

Figure 1 
Flowchart of participants.

Page 15/15 